\title{
Simplification Of Painting Images For Tactile Perception By Visually Impaired Persons
}

\author{
Katerine ROMEO ${ }^{1[0000-0001-6175-6248]}$, Marion CHOTTIN ${ }^{2}$, Pierre ANCET $^{3}$, \\ Christele LECOMTE ${ }^{1}$, Edwige PISSALOUX $^{1[0000-0001-9891-2531]}$ \\ ${ }^{1}$ Rouen Normandy University, 76800 Saint-Etienne du Rouvray, FRANCE \\ ${ }^{2}$ ENS Lyon, 69007 Lyon, France, ${ }^{2}$ Burgundy University, 21078 Dijon, France \\ katerine.romeo@univ-rouen.fr
}

\begin{abstract}
The access to artworks by visually impaired people requires a simplified tactile representation of paintings. This paper presents the difficulties of direct transcription of artworks and the test results of simplification of the paintings done by Australian Aborigines which don't have purely visual elements such as shadows or perspective. The implemented methodology is bottom-up: it starts with tactile representation of basic elements relevant to the understanding of the whole painting, then their association into more complex concepts. The context of associations is explained through audio-description. The results of the tests with visually impaired persons are analyzed and explained.
\end{abstract}

Keywords: Segmentation, painting, tactile perception, multi-modal perception, blindness, visually impaired.

\section{Introduction: difficulties of a direct transcription}

When visually impaired people (VIP) go to a museum, they encounter difficulties with the perception of artworks. To benefit from the beauty, emotion or information inspired by these objects, a tactile representation can be one of the solutions for blind persons. The museums for art and science are traditionally organized prominently for the sense of sight, and this organization has been based for a long time on the prohibition of touching the artwork. However, the sense of touch conveys information and aesthetic pleasure as well as the sense of sight. The cognitive virtues of touching have been recognized since Aristotle, and today they are being rediscovered and measured [11], [12]. The aesthetic virtues of contact through touch have been known ever since antiquity and they have been honored regularly in the history of art [13], [14]. Besides, several blind persons such as Marie Heurtin and Helen Keller testify about their tactile and aesthetic experiences [15], [16].

The direct transcription of a painting into a tactile material is possible with different techniques such as embossing, thermoforming, serigraphy, thermo-graphical printing or 3D printing [1]. Examples of realizations with different materials may be touched in the Musée des Beaux Arts of Rouen (France) or the Pinacotheca de Brera of Milan (Italy). Some recommendations for the transcription of documents [2] specify minimum distances between graphical elements of $2.3 \mathrm{~mm}$ in order to respect the 
tactile acuity. This distance is similar to the gap between the dots in Braille letters. Kinesthetic and proprioceptive perception should be taken into account when geometrical characteristics are used in graphics, such as length of segments or angle: distinction of small contours and very small changes in directions in segments could be ignored and not perceived otherwise. Even when respecting these rules and the original page layout, the result of the transcription of painting images present an overabundance of information which can be discouraging to VIP's.

Another problem in the transcription of paintings is the presence of shadows difficult to recognize when included in the contours of an object. The deformation of objects through perspective, which is usually used for depth perception, may not be as intuitive to VIP's who have to be taught ego-centered and exo-centered views of the body, buildings or objects. Some very interesting work has been done in automatic image transcription of very simple educational graphics [4] [5] that can be applied to tactile transcription of some simple paintings or graphics, but it is necessary to decompose paintings to give access to the meaning of the global picture. Some terms or expressions may mean nothing to congenitally blind persons as mentioned such as "face view" and "profile", or "shadow" and "perspective". However, color names and the semantic field of light should not be banned: these terms are always associated, even with VIP's, to other sensations, (such as the yellow color with heat) and to emotions (such as the red color with anger) and then they can be extremely meaningful [17].

Thus, a direct transcription of the painting on a tactile surface is not relevant for VIP's as it does not allow appropriate understanding of its content and appreciation of the esthetic quality of the artwork. A multi-modal approach is necessary, accompanying the graphical representation with an audio description of the shapes of the objects represented in the painting as well as their location and role [6] [7]. The audio description should use the specific words and definitions from the specific vocabulary used by VIP's [8] [9].

This paper proposes a multi-modal representation of paintings in an interactive way. The paper is organized as follows. Section 2 presents the difficult problem of conservation of meaning after a transcription into a tactile representation. Section 3 discusses the proposed multi-modal representation and the tests with visually impaired persons. Finally we present in section 4 our conclusions and some reflections on future work.

\section{Conservation of meaning}

First of all, an artwork is dependent on its visual intensity as explained by De Coster and Loots [3]. It is the degree of vision one can use to understand a painting or a sculpture which can be considered as a visual narrative. Blind people are conscious of this important visual concept on art. The Museums often propose audio-guides or art teachers to explain the artworks in the exhibitions but the explanations are often on the context and not the visual appearance. The cognitive effort produced by visually impaired persons to catch the meaning of an artwork is usually made by the associa- 
tion of the story behind the creation of this artwork and its perceptual features. Of course art is not only about its appearance but also history and philosophy. A meaningful art education would include both explanations and tactile perception. Different details can be presented in an analytical way, including all the eye-catching points of interest. However these details don't have a great significance if the context is not introduced. Only when the global meaning of the painting is understood, can blind persons reach an aesthetic experience [10]. We should also add that aesthetic experiences are not always pleasurable - some are meant to disturb, to perplex or to question - and this can also be described and aroused by the narrative experience, or felt by audio-tactile perception.

The tactile perception is a singular approach to feel a painting: this information is not complete as it is. And it is the same incomplete information when we consider solely the visual appearance of an artwork for seeing people. All of the available information is necessary to explore the artwork in a tactile manner, to understand the shape of its different parts and the relation between them, the context. People, visually impaired or not, generally do not have the experience to explore an artwork tactilely. This is why a multi-modal representation of artworks seems to be quite relevant.

\section{Multi-modal representation}

To evaluate the relevance of the proposed multi-modal representations of paintings, the bottom-up methodology is implemented. It starts with tactile representation of basic elements relevant to the whole painting understanding, then their associations into more complex concepts and finally into the whole image. The tactile shapes, the context of their associations and the global meaning of the painting are explained with audio-description.

\subsection{Experimental environment}

This bottom-up methodology was implemented while testing the aboriginal painting "Dream of the snake" from the Australian painter Warlimpirrnga Tjapaltjarri which is in the Museum of Quai Branly in Paris, France (see Fig. 1 left). It should be noticed that the objects on aboriginal paintings have no edges: they are composed of elementary dots that form different shapes. There are several important reasons for this choice of painting: first of all, this artwork is composed by simple geometric forms, which can be reproduced on a tablet with haptic feedback and that can be recognized through non-expert touch from a user. The second reason is that this painting does not have purely visual elements like shadows, reliefs or perspectives that congenitally blind persons could not understand. Finally, the third reason is that this artwork has a tactile dimension because the original paintings were done on the soil, with fingers digging in the sand [18].

These characteristics of aboriginal paintings guided our selection of a touch stimulation device. The University of Lille's touch-stimulating prototype STIMTAC was 
selected (Fig. 1 right). This device is designed for displaying tactile textures through scanning the STIMTAC surface with a finger.
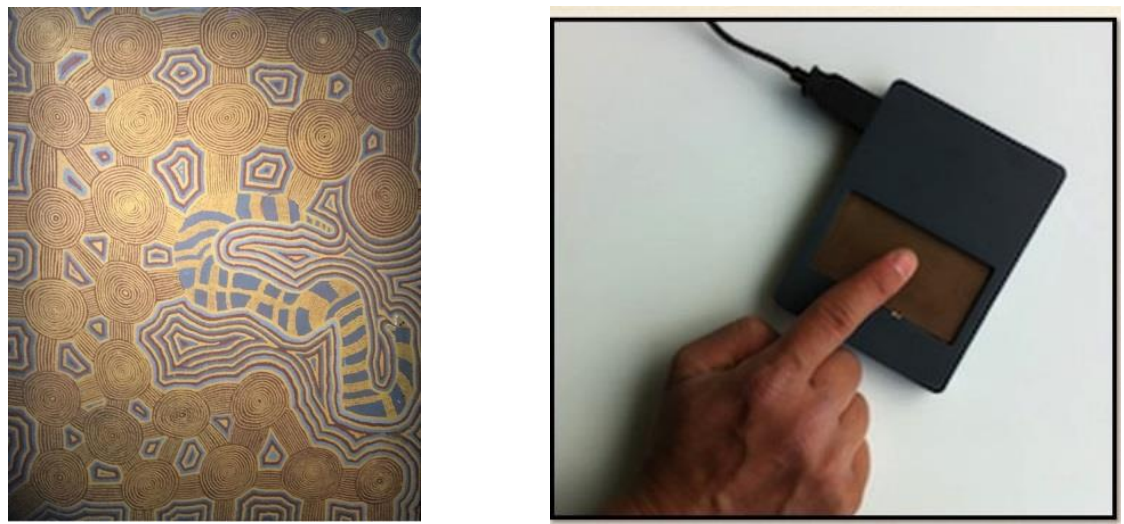

Fig. 1. The painting "Dream of the snake" and the Touch stimulation device STIMTAC

\subsection{Participants}

The evaluation of our experiments has been achieved through two series of tests. The first tests were executed to verify the psycho-cognitive perception of stimuli generated by the STIMTAC tactile stimulation device. Three visually impaired persons with one of them congenitally blind, gave us the first results of perception of different textures and forms generated by STIMTACT that supports friction reduction by means of a squeeze film effect.

The second set of tests were completed with twelve participants, two of them congenitally blind, six adventitiously blind and four with severe visual impairment. The test was based on the discovery of the aboriginal painting "Dream of the snake". The evaluation was done by VIP's where $58 \%$ of the participants were men and $42 \%$ women. The majority of the participants were more than fifty years old and some were in their twenties. A great number were retired and $25 \%$ were employed (See Fig. 2). All of the participants were expecting a new haptic tool which could help them to discover some artwork through touching.
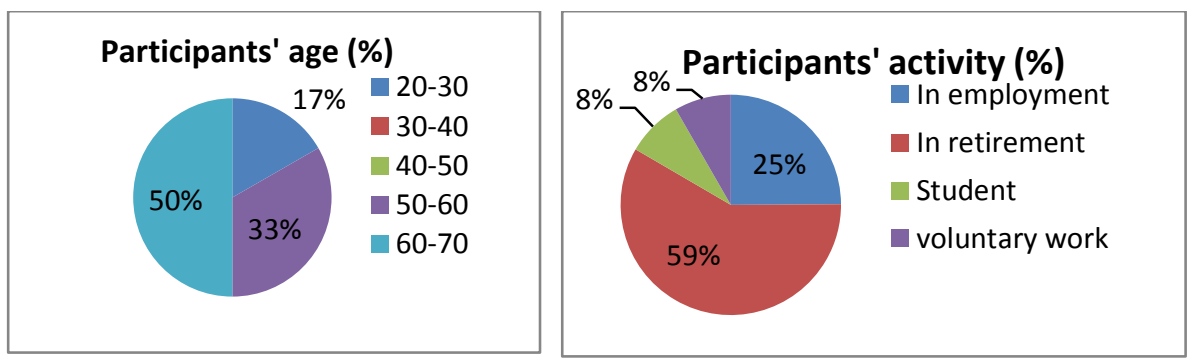

Fig. 2. Participants to the evaluation of the painting on the tactile tablet STIMTAC. 


\subsection{Results}

The participants to the tests appreciated the idea of discovering a painting in a tactile way. The decomposition of the painting "Dream of the snake" into small elements like dots, lines and composite figures (see Fig. 3) was intended to test the ability to recognize simple forms in the different tactile perception of friction.

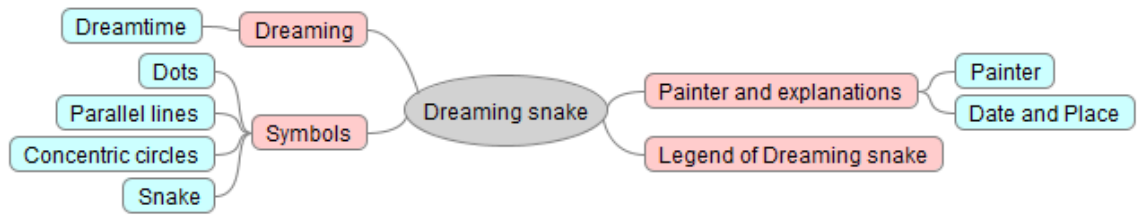

Fig. 3. The decomposition of the aboriginal painting "Dreaming snake" in small elements and the description of the context.

The stimulation of the vibro-tactile device STIMTAC creates the perception of textures and models the interaction between the finger and the surface of the pad. The perception may be the texture of an object or the smoothness/roughness of the explored area comparing to the strength of the finger's contact and the orientation of its movement.

The experiment was carried out in three phases: First of all, a texture detection test was made. Two different textures were shown side by side and the participant had to feel with a finger on the screen of the STIMTAC tablet, the textures and the limit between them. Then, the participant had to indicate which one of the two textures presented a rough surface. The detection results of this experiment with textures are shown in Fig. 4. The majority of VIP's detected the surface with the rough texture but the novel nature of the signal surprised some of the participants who were expecting to touch some hard material, and they could not name what they felt as "surface with friction" or "rough surface" or anything else. The white textures present a smooth surface and the dark textures create a friction-like perception.
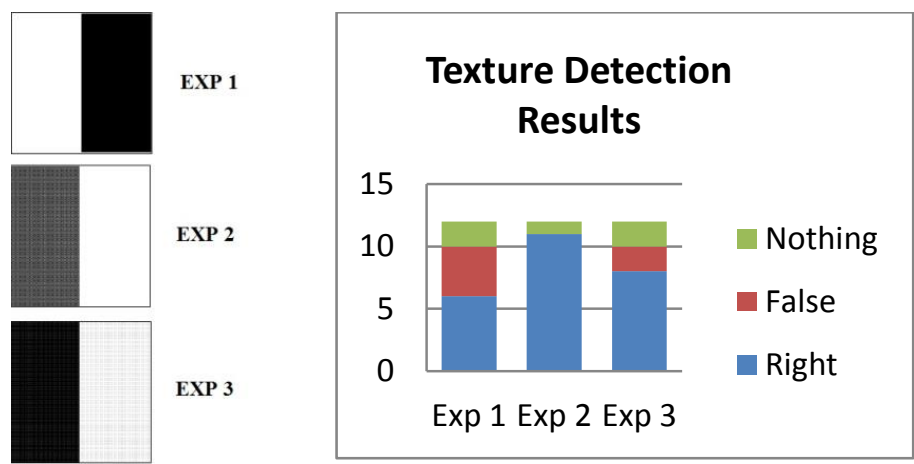

Fig. 4. Results on texture detection tests with visually impaired participants. 
The next experiment had a progressive approach in the detection of figures, from simple to complex shapes. Apart from the explanations on the experiment and the test progress, no help was provided.to the participants, no feedback was given. The participants had to describe what they detected. Circular shapes were difficult to recognize, the first figures were dots (See Fig. 5. - pictures 1,2,3) and the aim of this experiment was to detect one or several textured patches on the surface. The second set of figures was parallel lines and concentric circles (Fig. 5. - pictures 4, 5,6). The aim was to feel the transition from one texture to another between the lines and to feel the white areas between them, as well as the center of the circles. The third set was more complex figures as assembled from simple forms (Fig. 5. - pictures 7, 8) where the global perception was asked. Finally the snake (Fig. 5. - picture 9) was scanned with one finger and detected partially or as a global shape. It is a difficult exercise to name the perception of a complicated shape without help. However it can be observed that the detection results are improving with experience as shown in Fig. 6, and the participants have some perception of the global shape on the screen.

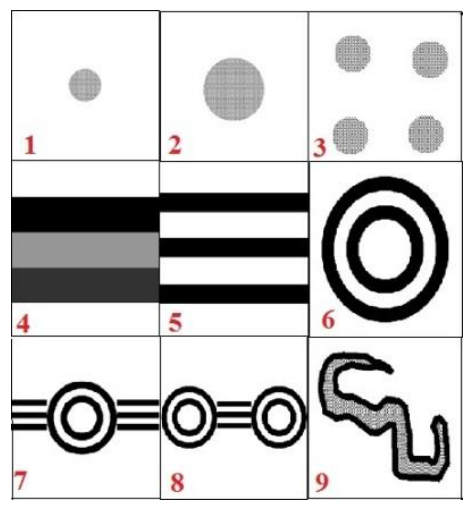

Fig. 5. Simple and complex figures presented for detection by VIP

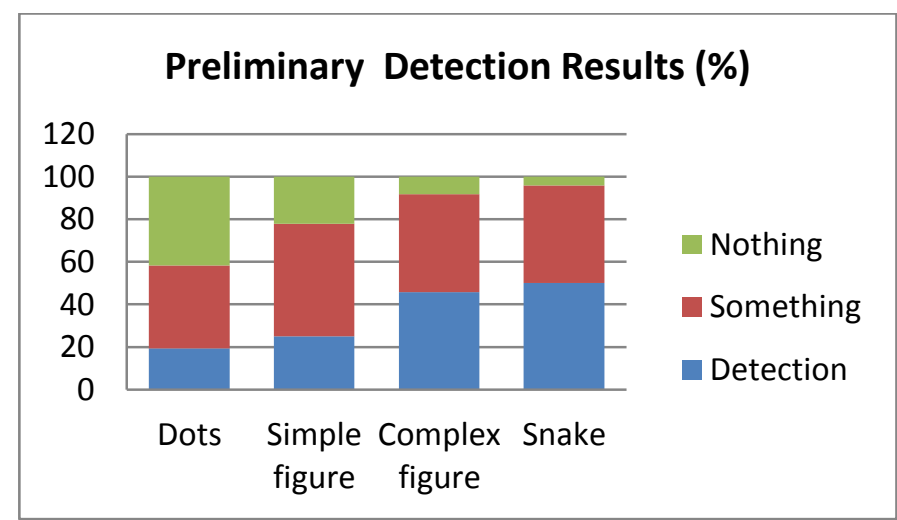

Fig. 6. Preliminary Results from the tests with the STIMTAC tablet, on simple and complex figures being part of the painting "The dream of the snake". 
The third phase of the experiment continued with the same figures, but this time with an audio signal describing the painting and the meaning of the symbols (Fig. 3) and it finishes with the legend of the snake in aboriginal Australia. The participants were asked if the audio-description helped the detection of the figures. Only fifty percent of them agreed because they found the haptic signal was not sufficiently in relief or in contrast. The alternation of textures and contours was expected. As the second part of the experiment was done without feedback, the figures could not have been learned. An audio-description during the tactile discovery is necessary. The majority of the participants agreed that the figures become meaningful with the context explained and that the tactile perception enhance the meaning given through the audio-description if a real tactile dialogue is provided.

The decomposition of the painting into small elements proved to be too analytic and the integration of these small details in the whole image was not sufficiently clear. We understand that the notion of detail is very well known by visually impaired persons but it appears that contextualizing these details more clearly is necessary.

The nature of the vibratory signal on the tablet did not allow for adequate recognition of defined figures. We had assumed that these vibrations would be more easily recognizable by VIP's who are experts in touching sensations. In fact, the tests showed us that it was not always the case: visually impaired persons perceive the vibrations as small very sensitive movements, not giving the sensation of a shape or the border between two textures. As a general rule, the non-expert persons in touching had better results in perception of figures.

\section{Conclusion}

This paper addresses the evaluation of the tactile representation of an aboriginal painting by visually impaired persons. The original bottom-up evaluation methodology was defined and implemented. The collected results show that the simplification of the tactile representation linked to the audio contextualization help the tactile exploration of the paintings. Inversely, audio-description is a guide to the tactile recognition of shapes. This is a relevant approach to make paintings accessible to visually impaired people and to all persons curious of tactile experiences who want to enhance their sensibility to art.

Our future work will explore the possibility of a tablet with tactile pins or points (taxels) that are more adequate for perception of the borders of figures. The participants to our tests asked for a greater size of tablet (A4) and they wish to touch with both hands and more than one finger. For the discovery of a painting it seems essential to explore bi-manually and pluri-digitally. For an efficient tactile transcription of paintings and accompanying audio-description, it is really necessary to work in close collaboration with visually impaired people in order to produce the most relevant results. This participative approach is a guarantee of the appropriation of the tool by the visually impaired people. 


\section{Acknowledgment}

The research on which this work is based is funded by CNRS, TETMOST project, and it is done with the collaboration between University of Rouen Normandy and Department of Seine Maritime and Espace Handicap of the University of Rouen.

\section{References}

1. Krivec, T., Muck, T., Fugger Germadnik, R., Majnaric, I., Golob, G. : Adapting Artworks for People Who Are Blind or Visually Impaired Using Raised Printing. Journal of Visual Impairment \& Blindness (Jan-Feb 2014), pp. 68-76

2. Bris, M. : Recommandations pour la transcription des documents. Service des Documents Adaptés pour Déficients Visuels, CNEFEI Suresnes (2003/11/17).

3. De Coster, K., Loots, G.: Somewhere in between Touch and Vision: In Search of a Meaningful Art Education for Blind Individuals. International Journal of Art \& Design Education. Oct2004, Vol. 23 Issue 3, p326-334.

4. Haddad, Z., Chen, Y., Krahe, JL.: Image Processing and Pattern Recognition Tools for the Automatic Image Transcription. In: Computers Helping People with Special Needs, ICCHP 2016, p197-203, Linz, Austria (2016).

5. Chen, Y.: Analyse et Interprétation d'images à l'usage des personnes non-voyantes, Application à la generation automatique d'images en relief à partir d'équipements banalisés. Thesis Paris 8, Ecole Doctorale CLI, 27 Nov 2015

6. Fryer, L.: An Introduction to Audio Description: A Practical Guide. Routledge (2016)

7. Ginley, B.: Museums: A Whole New World for Visually Impaired People. Disability Studies Quarterly, vol.33, No.2, (2015) http://dsq-sds.org/article/view/4622/3945.

8. Kleege, G., Wallin, S.: Audio Description as a Pedagogical Tool. Disability Studies Quarterly, vol.33, No.2, (2015) http://dsq-sds.org/article/view/4622/3945

9. Mills, M.: Listening to Images: Audio Description, the Translation Overlay, and Image Retrieval. The Cine-Files, No.8, Spring 2015, http://www.thecine-files.com/listening-toimages-audio-description-the-translation-overlay-and-image-retrieval/

10. Lorin-Etuy, D., Bauweens, M.: Comment le cerveau réagit-il à l'art? Hors-Série Art, Oct 2016, pp64-69

11. Aristote : De l'âme, Paris, GF Flammarion, 1999

12. Hatvelle, Y., Streri, A., Gentaz, E. : Toucher pour connaître. Psychologie cognitive de la perception tactile manuelle, Paris, PUF, 2000

13. Dent, P. (ed.) Sculpture and Touch. Routledge, 2014

14. Marinetti : Le tactillisme. Manifeste futuriste, in Giovanni, L. : Futurisme. Lausanne, Editions l'Âge d'Homme, 1973

15. Keller, H. : Histoire de ma vie. Paris, Payot, 2001

16. Villey, P. : Le Monde des aveugles. Essai de psychologie, Paris, Flammarion, 1914

17. Verine, B. (ed.) : Dire le non-visuel. Approches pluridisciplinaires des discours sur les perceptions autres que la vue. Presses universitaires de Liège, 2014

18. Glowczewski, B. « Du rêve à la loi chez les Aborigènes : mythes, rites et organisation sociale en Australie », Ed. PUF, Paris, 1991 